\title{
30. PALEOMAGNETIC RESULTS FROM DSDP SITE 398
}

\author{
G. E. Morgan, Department of Earth Sciences, University of Leeds, Lềeds LS2 9JT, U.K.
}

\begin{abstract}
Paleomagnetic investigations have been conducted on over 300 sediment samples from sub-bottom depths of between 125 and 1740 meters, and ranging in age from late Pleistocene to Early Cretaceous. Although NRM intensities show a considerable total variation, the section can be divided into clearly defined intervals within which the range of intensities is rather narrow. The transitions from one intensity interval to another generally coincide with lithological changes, particularly color changes, and the most marked intensity change corresponds almost exactly with a hiatus between Cenomanian and younger sediments. Most samples have been subjected to progressive a.f. demagnetization and the majority reached good stable end-points at fields of between 100 and $300 \mathrm{Oe}$. There is some evidence that the stable remanence is carried by both magnetite and hematite, and that the magnetite and hematite magnetizations are in essentially the same direction. The deviation of the hole from vertical below 1000 meters introduced an uncertainty into the remanence inclinations in unbedded samples. However, by assuming the hole deviation azimuth to be constant with depth and using it as a fixed reference, it was possible using clearly bedded samples to demonstrate that their remanence declinations were very similar, and to determine an average remanence declination with respect to the hole deviation azimuth. It was then possible to apply an appropriate correction to the inclination of unbedded samples. Down to the upper Santonian, approximately equal numbers of normal and reversed stable magnetizations are present; below this, virtually all stable magnetizations are normal. The sampling density does not allow the recognition of a detailed polarity sequence, but the results do not support the existence of an appreciable reversed interval within the Aptian corresponding to marine magnetic anomaly $M O$, and they suggest that the long Cretaceous normal interval extends back at least as far as the middle Barremian. Stable inclinations show some scatter but, when averaged over à dozen or so samples, are consistently shallower than would be expected from continental reconstructions for the periods of time represented, and it is tentatively suggested that this may be due to sediment compaction.
\end{abstract}

\section{INTRODUCTION}

Sampling for paleomagnetism at Site 398 was attempted on all cores below the depth (about $125 \mathrm{~m}$ ) where sediment undisturbed by drilling was first encountered. Whenever possible, three or four samples were taken from each core, with fewer samples from cores where recovery was poor. In the fissile shales of lithologic Unit 4, sampling was difficult and only one or two samples were obtained per core. The total of 302 samples averages a sampling density of about two samples per 9.5-meter core, and represents all the major lithological types encountered. Samples are generally pure to marly nannofossil oozes and chalks in the upper part of the hole; mudstones, claystones, and shales predominate in the lower part. Debris flows, mudchip conglomerates, and the thin sandy layers were not sampled. Samples were generally $2.5 \mathrm{~cm}$ in diameter and about $2.5 \mathrm{~cm}$ long, and were oriented only with respect to the long axis of the hole.
The natural remanent magnetization (NRM) of about 150 samples was measured onboard Glomar Challenger; about half of these samples were subjected to progressive alternating field (AF) demagnetization and measurement up to maximum fields of 300 or 400 Oe. The shore-based study involved completion of the NRM measurements of all samples and (except for about fifty samples which are very weakly magnetized and eight samples reserved for other studies) the progressive AF demagnetization and measurement up to fields of 250 to 1800 Oe of all samples not demagnetized onboard ship. Both on-board ship and in the shore study, measurements of remanent magnetization were carried out using a Digico slow-speed spinner magnetometer (Molyneux, 1971). Magnetizations of $1.0 \times 10^{-6} \mathrm{emu} /$ $\mathrm{cm}^{3}$ and greater were measured using an integration time of $2^{6}$ seconds, and weaker magnetizations required $2^{7}$ seconds. For all magnetizations of less than $0.3 \times 10^{-6} \mathrm{emu} / \mathrm{cm}^{3}$, at least one and generally two or more repeat measurements 
were made and a mean result computed. All measurements were performed using the full six-spin measuring procedure.

\section{RESULTS}

The results of paleomagnetism studies for Site 398 are summarized in Table 1.

\section{NRM Intensities}

The variation of NRM intensity with depth is illustrated in Figure 1. Although intensity of magnetization varies by more than four orders of magnitude, it is possible to divide the section into clearly defined intervals within which the range of intensity values is relatively narrow. The transition between the high intensities of the 125- to 327-meter interval and the low intensities in the interval 366 to 510 meters corresponds to a change from typically gray-green colors of the softer oozes above, to paler creams of the firmer chalks below. Similarly, the transition from the low intensities between 366 and 510 meters to the moderate and high intensities between 530 and 947 meters seems to be related to color: brown or red coloration is completely absent above this transition, and commonly occurs below.

Within the 530-to 947-meter interval, most samples have some shade of brown or red and, generally, the intensity of magnetization is related to the strength of this coloration. The few samples with very weak magnetization $(<1.0 \times$ $10^{-7} \mathrm{emu} / \mathrm{cm}^{3}$ ) always completely lack these colors, and are generally cream or greenish. Samples with slightly stronger intensities of between $1.0 \times 10^{-7}$ and $2.0 \times 10^{-6} \mathrm{emu} / \mathrm{cm}^{3}$ always show pale shades of red or brown. Samples with intensities of between 2.0 and $50 \times 10^{-6} \mathrm{emu} / \mathrm{cm}^{3}$ (the majority of samples in this interval) generally have medium to deep shades, and very strongly magnetized samples with intensities greater than $50 \times 10^{-6} \mathrm{emu} / \mathrm{cm}^{3}$ are generally medium to dark red or brown. Within this interval, maximum intensity increases gradually with depth from about $1.0 \times 10^{-5} \mathrm{emu} / \mathrm{cm}^{3}$ to over $1.0 \times 10^{-4} \mathrm{emu} / \mathrm{cm}^{3}$ and the range of intensities narrows gradually from the top of the interval to the base corresponding to the gradual increase with depth of the proportion and intensity of red/brown coloration.

The marked transition from the high intensities of the lower part of the 530-to 947-meter interval to the low intensities below 947 meters corresponds closely to the boundary between the red and brown mudstones and claystones of lithologic Unit 3 and the gray mudstones and shales of lithologic Unit 4. This boundary is in Sample 398D-56-2, $19 \mathrm{~cm}$, at a hiatus between the Cenomanian and younger sediments. The transition in NRM intensities (see Table 1) is between Samples 398D-56-2, $13 \mathrm{~cm}$ and 398D-56-2, 50 $\mathrm{cm}$. If closely spaced samples were taken, the actual transition would probably be discerned at the base of the lowest $\mathrm{red} / \mathrm{brown}$ layer, which is at Sample 398D-56-2, $15 \mathrm{~cm}$.

Below the 947-meter transition, intensities remain low and show relatively little scatter to a depth of about 1670 meters, although average values increase slightly but regularly from about $3.0 \times 10^{-7} \mathrm{emu} / \mathrm{cm}^{3}$ at 947 meters to about $6.0 \times 10^{-7} \mathrm{emu} / \mathrm{cm}^{3}$ at 1670 meters. At 1670 meters, there is a transition to lower intensities which average about 1.0 $\times 10^{-7} \mathrm{emu} / \mathrm{cm}^{3}$. This transition corresponds approximately
TABLE 1

Summary of Paleomagnetism Data From Site 398

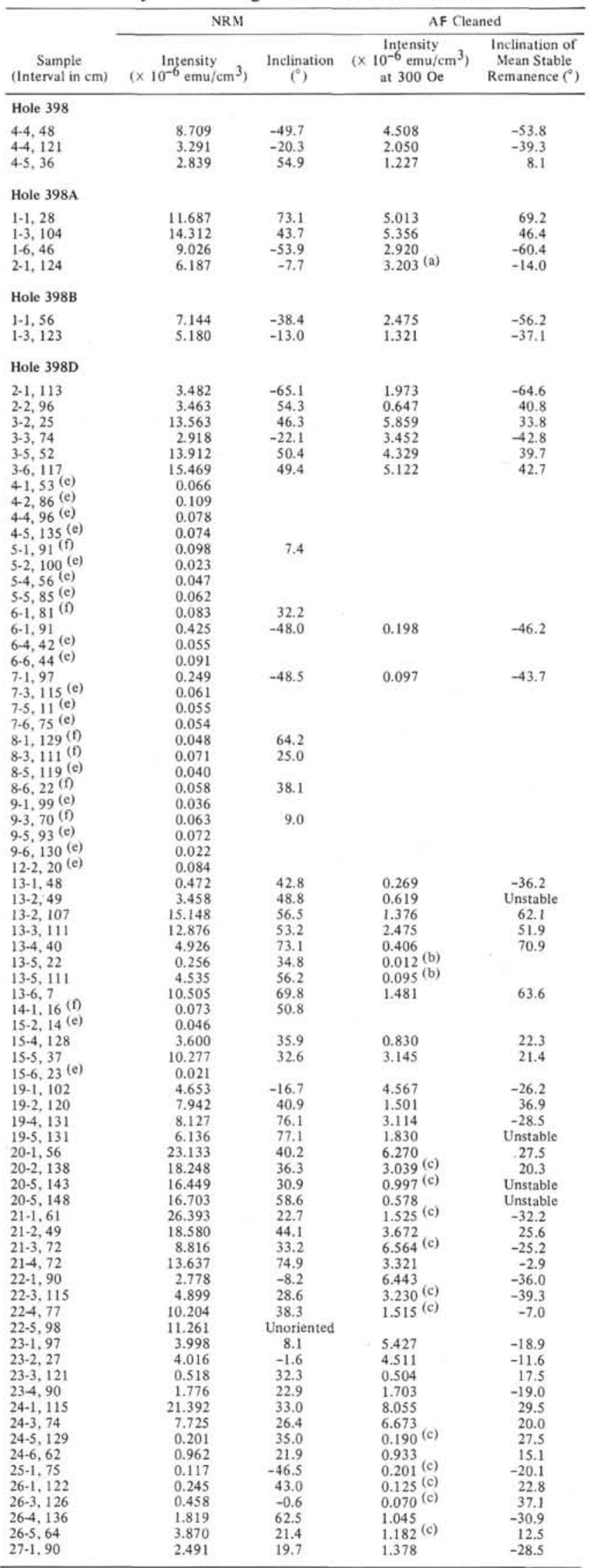


TABLE 1-Continued

\begin{tabular}{|c|c|c|c|c|c|c|}
\hline & NRM & & AF Clear & & & NRM \\
\hline $\begin{array}{c}\text { Sample } \\
\text { (Interval in cm) }\end{array}$ & $\begin{array}{c}\text { Intensity } \\
\left(\times 10^{-6} \mathrm{emu} / \mathrm{cm}^{3}\right)\end{array}$ & $\begin{array}{l}\text { Inclination } \\
\left(\left(^{\circ}\right)\right.\end{array}$ & $\begin{array}{c}\text { Intensity } \\
\left(\times 10^{-6} \mathrm{emu} / \mathrm{cm}^{3}\right) \\
\text { at } 300 \mathrm{Oe}\end{array}$ & $\begin{array}{l}\text { Inclination of } \\
\text { Mean Stable } \\
\text { Remanence }\left({ }^{\circ}\right)\end{array}$ & $\begin{array}{c}\text { Sample } \\
\text { (Interval in cm) }\end{array}$ & $\begin{array}{c}\text { Infensity } \\
\left(\times 10^{-6} \text { emu/ } \mathrm{cm}^{3}\right)\end{array}$ \\
\hline Hole 398D-Cont & inued & & & & $63-2,13$ & 0.425 \\
\hline $27-2,82$ & 5.685 & 31.8 & 3.623 & 18.3 & $63-3,72$ & 0.174 \\
\hline $27-3,147$ & 6.158 & 27.6 & 3.859 & 4.6 & $63-5,69$ & 0.222 \\
\hline $27-4,26$ & 16.228 & 18.3 & 5.835 & -13.9 & $65-2,119$ & 0.321 \\
\hline $28-2,16$ & 10.124 & Folded & 4.093 (c) & & $66-1,5$ & 0.269 \\
\hline $28-5,41$ & 0.245 & -16.1 & 0.272 (c) & -20.9 & $68-3,105$ & 0.231 \\
\hline $29-1,71$ & 2.830 & 34.1 & 1.684 & 22.7 & $68-5,77$ & 0.218 \\
\hline $29-5,106$ & 0.177 & 0.5 & $0.102^{(c)}$ & -13.1 & $69-2,87$ & 0.315 \\
\hline $29-6,81$ & 0.282 & -19.6 & 0.218 & -22.5 & $69-3,85$ & 0.335 \\
\hline $30-4,140$ & 2.515 & 26.8 & 5.268 & -13.7 & $70-1,22$ & 0.412 \\
\hline $30-5,75$ & 4.022 & -6.0 & 5.858 & -20.4 & $70-3,50$ & 0.525 \\
\hline $31-1,63$ & 0.835 & 74.3 & 0.909 & -20.5 & $71-3,27$ & 0.438 \\
\hline $31-3,77$ & 3.125 & 6.7 & 4.568 & -9.8 & $72-1,12$ & 0.649 \\
\hline $32-1,110$ & 16.139 & 32.2 & 2.774 & 8.7 & $72-1,89$ & 0.438 \\
\hline $32-2,56$ & 12.735 & 37.9 & 4.944 & 14.9 & $72-4,87$ & 1.224 \\
\hline $32-5,29$ & 11.002 & 41.4 & $1.482^{(c)}$ & Unstable & $72-5,83$ & 0.226 \\
\hline $32-6,15$ & 21.787 & 58.5 & 2.336 & -11.1 & $73-2,37$ & 0.357 \\
\hline $33-1,67$ & 26.972 & 46.8 & 1.513 & 41.1 & $73-5,22$ & 0.495 \\
\hline $33-2,32$ & 14.632 & 75.2 & $1.120^{(c)}$ & Unstable & $74-1,65$ & 0.247 \\
\hline $33-4,143$ & 10.287 & 27.5 & 4.338 & 21.3 & $74-2,6$ & 0.514 \\
\hline $34-1,101$ & 23.043 & 52.0 & 3.982 & 51.8 & $75-1,95$ & 0.429 \\
\hline $35-2,103$ & 1.572 & 64.3 & 0.369 & -61.8 & $75-3.19$ & 0.642 \\
\hline $35-3,137$ & 15.905 & 8.0 & 4.129 & -22.0 & $76-3,74$ & 0.662 \\
\hline $35-4,68$ & 6.309 & 48.2 & 1.292 & -22.7 & $77-2,84$ & 0.546 \\
\hline $36-1,127$ & 13.253 & -3.0 & 10.746 & -10.0 & $78-3,106$ & 0.481 \\
\hline $36-2,116$ & 2.557 & -11.1 & 1.658 & -11.5 & $79-3,16$ & 0.587 \\
\hline $36-4,82$ & 6.072 & -26.4 & 7.310 & -35.6 & $80-4,82$ & 0.599 \\
\hline $36-6,139$ & 1.177 & 21.8 & 1.160 & -17.5 & $82-1.75$ & 0.509 \\
\hline $37-1,28$ & 30.713 & 41.8 & 6.030 & 5.6 & $84-1,45$ & 0.226 \\
\hline $37-4,23$ & 5.367 & 15.7 & 5.717 & -18.2 & $85-2,44$ & 0.395 \\
\hline $38-4,149$ & 36.706 & 50.3 & 6.728 & 35.0 & $86-2,30$ & 0.531 \\
\hline $38-5,90^{(f)}$ & 0.098 & 56.9 & & & $86-4,13$ & 0.565 \\
\hline $39-1,128$ & 38.836 & 63.0 & 3.336 & 67.0 & $87-1,11$ & 1.055 \\
\hline $39-2,149$ & 11.730 & 65.5 & & & $87 \cdot 2,88$ & 0.500 \\
\hline $39-4,130$ & 8.088 & -81.6 & & & $88-2,88$ & 0.280 \\
\hline $40-2,27$ & 38.973 & 50.8 & 0.935 & -18.8 & $88-5,66$ & 0.594 \\
\hline $40-3,69$ & 37.587 & 17.7 & & & $89-2,17$ & 0.165 \\
\hline $40-5,54$ & 25.181 & 59.5 & & & $90-1,14$ & 0.926 \\
\hline $41-2,127$ & 30.729 & $20.5^{\text {(a) }}$ & 3.651 & Unstable & $91-1,10$ & 0.381 \\
\hline $41-3,51$ & 33.100 & 14.3 & 5.290 & -14.5 & 914,141 & 0.326 \\
\hline $41-4.124$ & 28.795 & 52.9 & 3.357 & 36.0 & $92-1,39$ & 0.473 \\
\hline $41-6,18$ & 11.388 & 4.7 & 3.521 & -40.7 & $92-2,137$ & 0.239 \\
\hline $42-1,106$ & 4.264 & -10.6 & 7.222 & -30.0 & $93-2,120$ & 0.465 \\
\hline $42-2,123$ & 2.177 & 72.7 & 5.721 & -37.2 & $93-3,30$ & 1.117 \\
\hline $42-3,72$ & 10.650 & 6.4 & 3.115 & -28.7 & $95-1,115$ & 0.704 \\
\hline $43-2,123$ & 9.313 & -25.7 & 4.967 & -34.1 & $96-2,13$ & 0.605 \\
\hline $43-3,104$ & 6.095 & -3.3 & 7.755 & -34.3 & $96-4,89$ & 0.453 \\
\hline $43-4,49$ & 13.780 & -29.5 & 11.055 & -32.5 & $97-1,77$ & 0.530 \\
\hline $44-1,130$ & 12.349 & 42.6 & 2.619 & 21.4 & $97-5,13$ & 0.574 \\
\hline $44-2,14$ & 13.446 & 54.3 & 6.723 & 46.9 & $99-5,34(\mathrm{~g})$ & 0.329 \\
\hline $44-6,19$ & 12.700 & -18.2 & 6.043 & -39.9 & $100-3,65$ & 0.655 \\
\hline $45-1,24$ & 10.800 & 63.6 & $3.800^{(c)}$ & Unstable & $100-4,88$ & 0.172 \\
\hline $45-3,80$ & 9.383 & 40.1 & 1.702 & Unstable & $100-5,64$ & 0.446 \\
\hline $45-5,141$ & 34.580 & 57.7 & 9.426 & 49.7 & $101-4,13$ & 1.000 \\
\hline $46-1,44$ & 34.890 & 67.2 & 4.689 & 79.0 & $101-5,118$ & 0.459 \\
\hline $46-3,24$ & 35.606 & 23.6 & 6.149 & -4.9 & $102-3,50$ & 1.008 \\
\hline $46-4,39$ & 60.035 & 32.2 & 9.786 & 31.1 & $102-6,61$ & 1.111 \\
\hline $47-1,9$ & 56.808 & 61.2 & 11.422 & 50.4 & $104-1.59$ & 0.414 \\
\hline $47 \cdot 2,35$ & 38.046 & 39.1 & 7.223 & Unstable & $104-2,59$ & 0.422 \\
\hline $47-4,111$ & 43.500 & -3.1 & 13.171 & -27.0 & $106-2,74$ & 0.771 \\
\hline $48-2,101$ & 34.855 & 41.4 & 9.039 & 26.4 & $106 \cdot 5,50$ & 0.520 \\
\hline $48-3,78$ & 6.382 & 7.5 & 10.387 & -40.4 & $107-1,72$ & 0.329 \\
\hline $48-5,27$ & 25.663 & 26.5 & $3.176^{(a)}$ & Unstable & $107-2,13$ & 0.342 \\
\hline $49-1,41$ & 60.966 & 43.1 & 2.592 & Unstable & $108-6,43$ & 0.599 \\
\hline $50-1,72$ & 47.400 & 36.8 & 4.461 (c) & Unstable & $109-2,78$ & 0.490 \\
\hline $50-4,146$ & 69.689 & 55.3 & 2.681 (a) & Unstable & $109-3,16$ & 1.423 \\
\hline $50-5,40$ & 66.671 & 46.4 & 3.575 & Unstable & $111-2,111$ & 0.763 \\
\hline $51-1,45$ & 77.186 & 49.5 & 13.970 & -40.4 & $111-4,109$ & 3.597 \\
\hline $51-2,90$ & 74.000 & 35.4 & 3.855 (d) & Unstable & $112 \cdot 1,24$ & 1.008 \\
\hline $51-3.52$ & 79.000 & 37.8 & 13.712 (d) & Unstable & $112-5,105$ & 0.400 \\
\hline $54-2,93$ & 193.403 & 44.1 & 19.424 & 22.4 & $113-1,85$ & 0.258 \\
\hline $55-1,5$ & 263.083 & 15.5 & $10.205^{\text {(d) }}$ & 14.4 & $113-4,52$ & 1.102 \\
\hline $55-1,27$ & 247.424 & 41.0 & 32.075 & 21.9 & $114-1,85$ & 1.568 \\
\hline $55-1,54$ & 81.521 & 50.6 & $7.598^{\text {(d) }}$ & 21.0 & $114-4,40$ & 1.726 \\
\hline $56 \cdot 1,61$ & 125.788 & 35.9 & 59.863 & 23.9 & $115-1,16$ & 1.722 \\
\hline $56 \cdot 2,13$ & 88.337 & 30.6 & 56.387 & 27.0 & $115-2,105$ & 1.813 \\
\hline $56-2,50$ & 0.108 & 84.3 & & & $115 \cdot 3,66$ & 0.891 \\
\hline $56-3,112$ & 0.200 & 39.8 & & & $116 \cdot 1,5$ & 0.479 \\
\hline $56 \cdot 5,145$ & 0.152 & 20.1 & & & $117.3,90$ & 1.338 \\
\hline $56-6,8$ & 0.846 & 46.3 & $0.265^{(d)}$ & 30.9 & $117-4,126$ & 0.620 \\
\hline $57-1,31$ & 0.216 & 35.2 & & & $118-6,55$ & 0.135 \\
\hline $57-2,30$ & 0.171 & 51.0 & $0.152^{(\mathrm{c})}$ & 44.3 & $119-6,4$ & 0.720 \\
\hline $57-5,80$ & 0.275 & 35.1 & $0.120^{(\mathrm{c})}$ & 26.5 & $120-1,143$ & 0.829 \\
\hline $58-1,32$ & 0.296 & 18.7 & $0.178^{(c)}$ & 26.4 & $120-6,132$ & 0.824 \\
\hline $58-2,44$ & 0.314 & 77.0 & 0.163 & 40.7 & 121.1 .68 & 0.516 \\
\hline $59-3,148$ & 0.248 & 18.3 & $0.076^{(c)}$ & 22.9 & $121-3.78$ & 0.319 \\
\hline $59-4,132$ & 0.206 & 67.2 & $0.116^{(\mathrm{c})}$ & 48.9 & 121.5 .126 & 1.038 \\
\hline $59-6,6$ & 0.300 & 37.8 & $0.214^{(\mathrm{c})}$ & 31.1 & $122-1.39$ & 0.370 \\
\hline $60-1,39$ & 0.458 & 34.4 & 0.206 (c) & 19.9 & $122-3,41$ & 0.240 \\
\hline $62-2,147$ & 0.419 & 25.5 & $0.215^{(\mathrm{c})}$ & 34.4 & $122-6.78$ & 0.739 \\
\hline
\end{tabular}

TABLE 1-Continued 
TABLE 1-Continued

\begin{tabular}{|c|c|c|c|c|}
\hline \multirow[b]{2}{*}{$\begin{array}{c}\text { Sample } \\
\text { (Interval in } \mathrm{cm} \text { ) }\end{array}$} & \multicolumn{2}{|l|}{ NRM } & \multicolumn{2}{|c|}{ AF Cleaned } \\
\hline & $\begin{array}{c}\text { Intensity } \\
\left(\times 10^{-6} \text { emu } / \mathrm{cm}^{3}\right)\end{array}$ & $\begin{array}{l}\text { Inclination } \\
\text { ()) }\end{array}$ & $\begin{array}{c}\text { Intensity } \\
\left(\times 10^{-6} \mathrm{emu} / \mathrm{cm}^{3}\right) \\
\text { at } 300 \mathrm{Oe}\end{array}$ & $\begin{array}{l}\text { Inclination of } \\
\text { Mean Stable } \\
\text { Remanence }\left({ }^{\circ} \text { ) }\right.\end{array}$ \\
\hline $123-3,98$ & 0.337 & 40.0 & & \\
\hline $123-5,26$ & 1.672 & 38.2 & 1.123 & 31.4 \\
\hline $124-1,86$ & 0.689 & 19.9 & 0.161 & 33.9 \\
\hline $124-4,35$ & 1.179 & 34.8 & 0.495 & 23.2 \\
\hline $125-5,51$ & 0.312 & 53.0 & 0.065 & 34.1 \\
\hline $125-6,11$ & 1.546 & 19.1 & 0.221 & 43.7 \\
\hline $126-2,142$ & 0.730 & 55.1 & 0.172 & 44.0 \\
\hline $126-5,146$ & 0.866 & 62.1 & 0.445 & 57.9 \\
\hline $127-1,18$ & 0.342 & 39.8 & 0.136 & 40.0 \\
\hline $127-3,130$ & 0.158 & 59.2 & & \\
\hline $127-4,53$ & 0.804 & 36.5 & 0.078 & 37.9 \\
\hline $128-1,79$ & 0.438 & 70.1 & 0.204 & 46.1 \\
\hline $128-2,62$ & 1.354 & 29.5 & 0.674 & 20.0 \\
\hline $128-5,114$ & 0.272 & 58.5 & 0.131 & 48.6 \\
\hline $129-4,33$ & 0.308 & 49.5 & 0.176 & 25.3 \\
\hline $129-5,28$ & 0.348 & 15.0 & 0.081 (d) & 22.0 \\
\hline $129-6,72$ & 0.128 & 38.7 & & \\
\hline $130-1,64$ & 0.904 & 55.4 & 0.270 & 37.9 \\
\hline $130-3,15$ & 0.120 & 54.1 & & \\
\hline $130-6,60$ & 0.218 & 28.1 & & \\
\hline $132-1,83$ (f) & 0.075 & $27.8^{(h)}$ & & \\
\hline $132-2,33$ (e) & 0.012 & & & \\
\hline $132-2,109$ & 0.119 & $9.9^{(h)}$ & & \\
\hline $133-3,83$ (e) & 0.023 & & & \\
\hline $133-4,127$ (f) & 0.092 & 43.4 & & \\
\hline $133-5,76$ & 0.131 & $14.0^{(\mathrm{h})}$ & & \\
\hline $134-1,90$ & 0.114 & $71.5^{(\mathrm{h})}$ & & \\
\hline $134-2,41$ (f) & 0.055 & 76.2 & & \\
\hline $134-3.52$ (f) & 0.076 & 68.6 & & \\
\hline $135-1,124$ (f) & 0.050 & $29.2^{\text {(h) }}$ & & \\
\hline $135-3,96$ & 0.115 & 70.4 & & \\
\hline $136-2,52$ & 0.146 & 44.3 & & \\
\hline $136-3,86$ & 0.104 & $44.4^{(h)}$ & & \\
\hline $137-1,26$ & 0.114 & 33.6 & 0.093 & 32.0 \\
\hline $137-2,52$ (e) & 0.024 & & & \\
\hline $137-2,91$ & 0.112 & -44.3 & & \\
\hline $137-2,123$ & 0.120 & 50.3 & & \\
\hline $137-4,52$ (e) & 0.034 & & & \\
\hline $138-1,25$ (e) & 0.060 & & & \\
\hline $138-2,125$ & 0.263 & 54.0 & & \\
\hline
\end{tabular}

Note: $a=$ Intensity at $200 \mathrm{Oe}, \mathrm{b}=$ Intensity at $150 \mathrm{Oe}, \mathrm{c}=$ Intensity at $250 \mathrm{Oe}, \mathrm{d}=$ Intensity at $350 \mathrm{Oe}, \mathrm{e}=$ Weakly magnetized, NRM intensity value approximate only, inclination value insufficiently reliable for inclusion in table; $f=$ Weakly magnetized, NRM intensity and inclination values approximate only. $g$ and $\mathrm{h}$ Samples from Cores 99 and deeper have had their cleaned inclinations corrected for the deviation of drilling from the vertical, NRM inclinations have been similarly corrected where a stable cleaned inclination was obtained, and in some cases, marked h, where no stable inclination was obtained. See text for details.

to the boundary between the predominantly dark shales and mudstones of lithologic Unit 4 above, and the very pale nannofossil limestones and gray claystones of lithologic Unit 5 below. The most weakly magnetized samples within Unit 5 are generally from the whitish limestone layers.

\section{Demagnetization}

Apart from the sixty or so samples mentioned above, all samples were subjected to progressive AF demagnetization and measurement up to fields of at least $250 \mathrm{Oe}$. The majority of samples were subjected to fields of at least $300 \mathrm{Oe}$, and many samples were demagnetized further to fields ranging up to $1800 \mathrm{Oe}$. Some representative examples of demagnetization behavior are shown in Figure 2. Samples from above the Upper Cretaceous hiatus are shown on the left part of the diagram, and samples from below this hiatus on the right. Samples were subjected to progressive demagnetization at successively higher fields, rather than blanket demagnetization at a single field, to more fully test the stability of the remanence. Wherever demagnetization produced regular movements of the remanence vector, generally caused by removal of a component with a positive (normal) inclination, demagnetization was continued until a satisfactory stable end-point had been reached.

Samples showed considerable variation in the amount of angular movement between the NRM direction and the

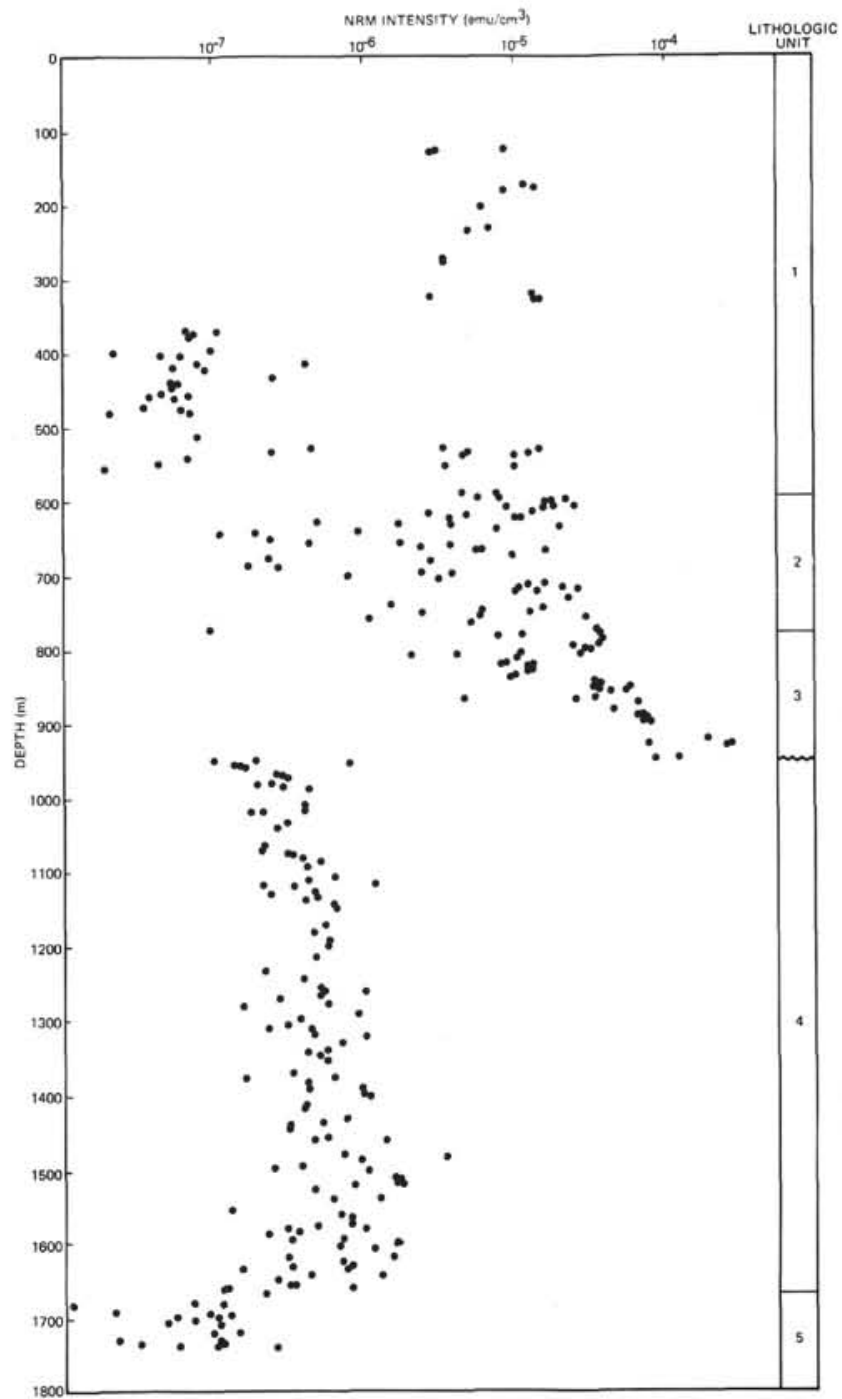

Figure 1. Variation of NRM intensity with depth.

end-point direction. In some samples, e.g., 398D-43-4, 50 $\mathrm{cm}$ and 398D-72-4, $87 \mathrm{~cm}$, there was virtually no movement, but in most there was a small movement, typically between $10^{\circ}$ and $30^{\circ}$; in other samples, e.g., 398D-42-2, $123 \mathrm{~cm}$ and $398 \mathrm{D}-129-4,33 \mathrm{~cm}$, there were much larger movements. The large movements were most common in samples from those red and brown sediments of lithologic Units 2 and 3 that had end-point directions with negative (reverse) inclinations; many of these samples had NRM directions with moderate or high positive inclinations. Where progressive demagnetization produced a regular movement of the remanence vector, the AF field required to reach an end-point was generally between 100 Oe (e.g., Samples 398D-22-1, $90 \mathrm{~cm}$ and 398D-57-5, $80 \mathrm{~cm}$ ) and $300 \mathrm{Oe}$ (e.g., Samples 398D-42-2, $123 \mathrm{~cm}$ and 398D-124-4, $35 \mathrm{~cm}$ ), although some samples from lithologic Units 4 and 5 required fields of up to $500 \mathrm{Oe}$ to complete the movement (e.g., Sample 398D-109-3, $16 \mathrm{~cm}$ ). Most samples showed wellgrouped end-points, and only 18 samples, mostly strongly magnetized red or brown sediments from lithologic Unit 3, were rejected because of unstable demagnetization behavior. Samples 398D-26-1, $122 \mathrm{~cm}$ and 398D-129-4, 33 

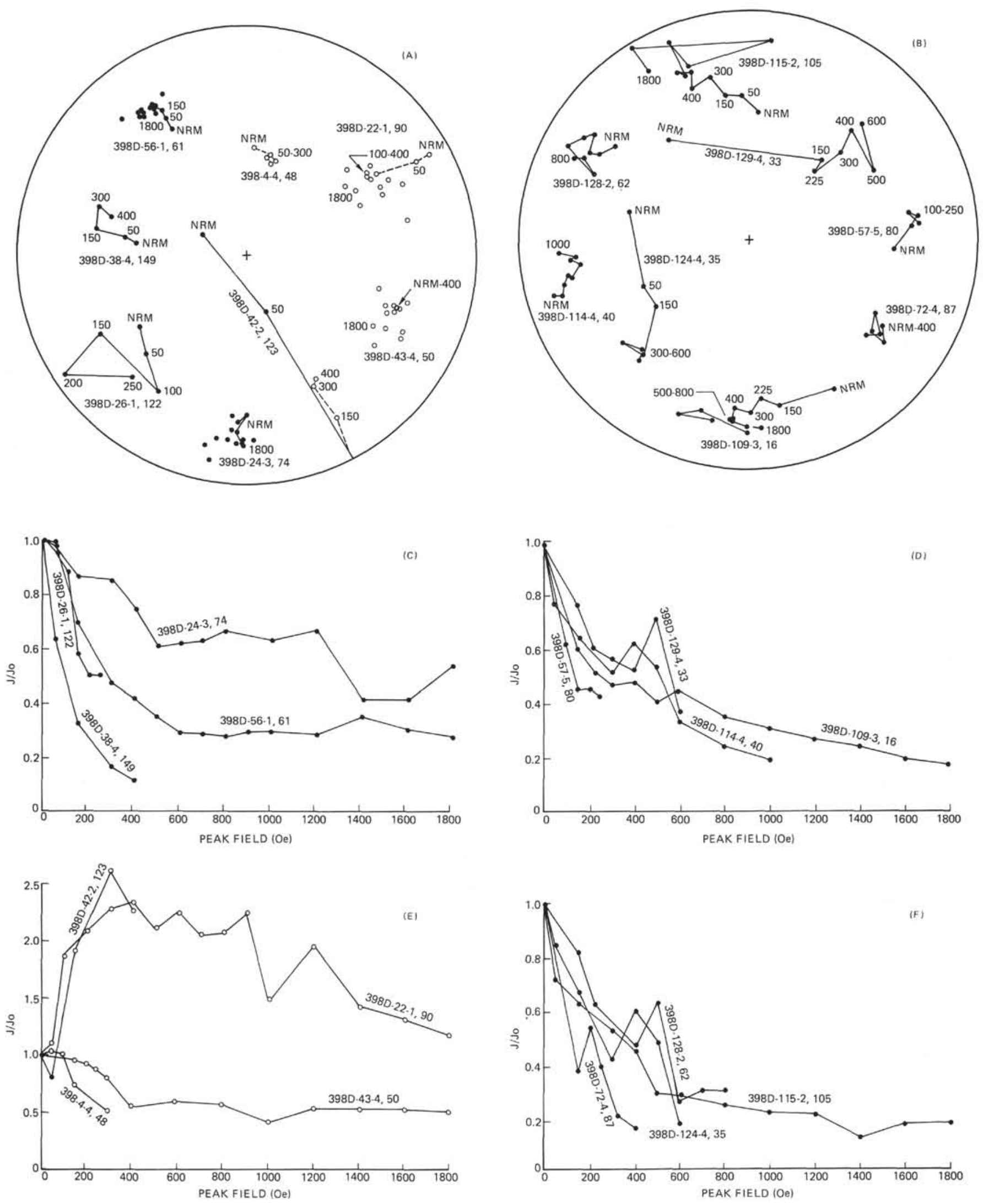

Figure 2. Representative examples of behavior during AF demagnetization. Equal area projections $(A)$ and $(B)$ show movements of remanence direction; solid circles indicate lower hemisphere and open circles upper hemisphere; declinations are arbitrary. Normalized demagnetization curves $(C)$ to $(F)$ represent the samples shown in $(A)$ and $(B)$. 
$\mathrm{cm}$ are typical of the few samples with poorly grouped end-points, and Samples 398D-38-4, $149 \mathrm{~cm}, 398 \mathrm{D}-72-4$, $87 \mathrm{~cm}$, and 398D-128-2, $62 \mathrm{~cm}$ are representative of the majority of samples and show closely grouped end-points.

About twenty samples, that had shown good directional stability at low and medium fields were progressively demagnetized to high fields of over $1000 \mathrm{Oe}$. Although some became unstable at intermediate fields, most showed moderate or good directional stability up to the maximum field of $1800 \mathrm{Oe}$; the behavior of some of these samples is illustrated in Figure 2. Samples from above the Upper Cretaceous hiatus generally showed closely grouped end-points between fields of about 150 and 400 or $500 \mathrm{Oe}$; at higher fields, these samples showed small (usually less than $10^{\circ}$ ), essentially random movements about the end-point. Demagnetization to high fields was generally difficult in samples from below the hiatus, because of their low intensities, but those samples successfully treated generally showed good end-points between fields of about 300 and $800 \mathrm{Oe}$, then fairly small movements at higher fields. These movements were generally caused by changes in declination rather than inclination, and appeared to be more or less centered on the previously established end-point.

The demagnetization curves of Figure 2 illustrate that about 50 per cent of the NRM of many samples is carried by grains with coercivities corresponding to demagnetizing fields of $300 \mathrm{Oe}$ or less, although the percentage is less in some samples, e.g., Samples 398D-24-3, $74 \mathrm{~cm}$ and $398 \mathrm{D}-43-4,50 \mathrm{~cm}$, and considerably more in others, e.g., Sample 398D-38-8, $149 \mathrm{~cm}$. Samples with reversed stable magnetizations and with a medium or high proportion of low coercivity components often showed an initial increase in intensity during demagnetization, presumably due to removal of an approximately anti-parallel normal overprint. As would be expected from consideration of the vector algebra of the situation, samples in which the NRM direction was controlled by a dominant normal overprint, e.g., Sample 398D-42-2, $123 \mathrm{~cm}$, showed an initial decrease before the main increase, whereas samples in which the NRM direction was controlled by a dominant reversed stable component, e.g., Sample 398D-22-1, $90 \mathrm{~cm}$, showed an immediate increase.

Demagnetization curves of samples which show good or moderate stability up to fields of $1800 \mathrm{Oe}$ indicate that, at least in these samples, (e.g., 398D-43-4, $50 \mathrm{~cm}$ and 398D$56-1,61 \mathrm{~cm})$, about half the remanence is carried by grains with coercivities corresponding to demagnetization fields of less than about $500 \mathrm{Oe}$, a small or negligible proportion is carried by grains with coercivities corresponding to fields of between 500 and $1800 \mathrm{Oe}$, and the large remaining part is carried by grains with coercivities corresponding to fields of over $1800 \mathrm{Oe}$. This suggests that the remanence is carried by both magnetite (low coercivities) and hematite (high coercivities). In most of the samples demagnetized to high fields, the mean of the directions obtained at fields of between about 150 and $500 \mathrm{Oe}$ is usually almost identical to the mean of the directions obtained at fields of between 500 and $1800 \mathrm{Oe}$. Thus, if the high coercivity components do reside in hematite, then this hematite magnetization is in essentially the same direction as the magnetite magnetization. Magnetite and hematite magnetizations with similar directions were also found in the Italian Scaglia Rossa pelagic limestone by Lowrie and Alvarez (1975).

For each sample, the magnetization directions from at least two, and often three or more demagnetization steps in the end-point group were combined to give a mean stable remanence direction for that sample; the inclination of this mean direction is quoted in the final column of Table 1. Altogether, 216 samples yielded stable end-point magnetizations. The majority of samples from below the Upper Cretaceous hiatus had intensities after demagnetization of less than $0.3 \times 10^{-6} \mathrm{emu} / \mathrm{cm}^{3}$ and so were subjected to at least two or three measurements after each demagnetization step. Thus, the mean stable magnetization for these samples is often the result of at least nine separate measurements.

\section{Drilling Deviation From Vertical}

Because there is no azimuthal orientation of the samples, it is not possible to determine the absolute declination of the remanence magnetizations. But, if the hole was drilled vertically, the sample orientation mark (which is parallel to the long axis of the core, i.e., the hole axis) provides a vertical reference which allows the true inclination of the remanence to be determined. If drilling deviates from the vertical, this will clearly introduce an error into the inclination measurements, the sense and amount of which depend on the amount of deviation and the relationship between the deviation direction and remanence direction.

Inclinometer measurements at Site 398 indicated that the hole was within $2^{\circ}$ of vertical down to 1000 meters, then the deviation gradually increased to $7^{\circ}$ at 1430 meters and $23^{\circ}$ at 1696 meters. Thus, uncorrected inclination measurements on samples from the lower part of the hole are uncertain. However, because some samples with clearly defined bedding laminations are present, it is possible (making certain assumptions) to apply a correction to the inclinations, and even to obtain information that could not be obtained from a vertical hole.

When drilling deviates from the vertical, the sample orientation mark no longer represents a vertical reference. But if we assume the sediments being drilled have horizontal bedding then in any sample with bedding laminations the angle between the remanence and the bedding is the true inclination. If the sample is oriented with the bedding horizontal, the sample orientation mark, representing the hole axis, will now be displaced from the vertical by an angle equal to the amount by which the hole axis deviates from the vertical. These relationships are illustrated in Figure 3, which shows that it is now possible to determine the declination of the remanence relative to the azimuth of the hole axis deviation. In the example given in Figure 3, the remanence declination is approximately $40^{\circ}$ counterclockwise relative to the azimuth of the hole axis. If we also assume that the azimuth of the hole deviation is constant with depth, then we can compare the remanence declination of bedded samples from different depths by using this fixed reference. Note that we still cannot determine absolute declinations of remanence because we do not know the absolute azimuth of the hole deviation, but we can examine the relative declinations of the remanence of widely spaced samples to see how well grouped they are, something we cannot normally do with a vertically drilled hole. If remanence declinations turn 


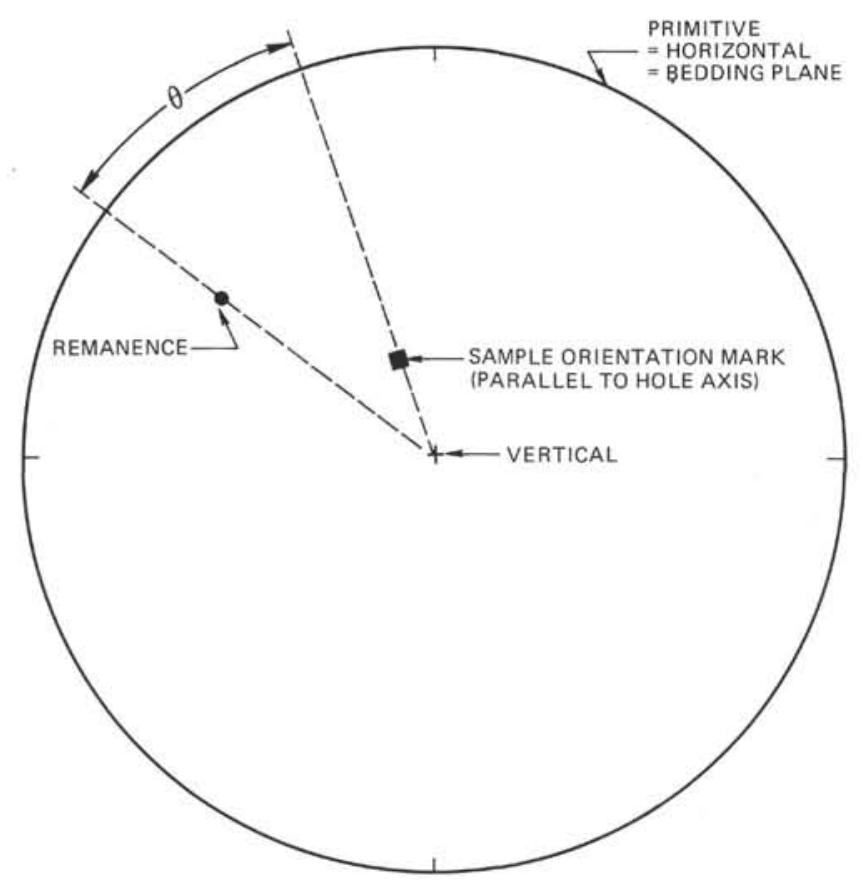

Figure 3. Projection showing relationship between bedding, remanence, and hole axis in a sample from part of hole which has deviated from the vertical. The declination scale is arbitrary. $\theta=$ declination of remanence with respect to azimuth of hole axis deviation.

out well grouped, this gives us some confidence in our measured magnetizations and allows us to correct the inclinations of unbedded samples. This can be done by calculating the average declination of the remanence with respect to the azimuth of the hole deviation using the bedded samples, and assuming that this average declination applies to all samples. Individual corrections carried out in this way will be slightly incorrect because of the scatter of the actual declinations about the average value used, but this effect should be averaged out over a number of samples.

A total of nine samples with well-defined bedding and stable end-point magnetizations, from depths of between 1520 and 1730 meters, was treated as described in the last paragraph. Figure 4 shows the mean stable magnetizations for these samples; the declinations being with respect to the azimuth of the hole deviation, which is assumed to be the same in each sample. Considering the errors inherent in this method, when dealing with deviation angles of only 6 to 12 degrees, the magnetizations are surprisingly well grouped, with a precision parameter, $k$, of 22.3 . If the same process is carried out on the NRM directions, the grouping is inferior, as would be expected, with a $k$ of only 4.8 . Unfortunately, there are no reversely magnetized samples from this part of the hole, so that it is impossible to check that normal and reverse samples have opposite declinations, but the results do indicate that normal samples have similar declinations, at least over this depth interval. The good grouping of stable remanence directions also supports the original assumption that the azimuth of the deviation was constant. It is also consistent with the assumption that the bedding is horizontal; but note that a sequence with a constant dip in the same

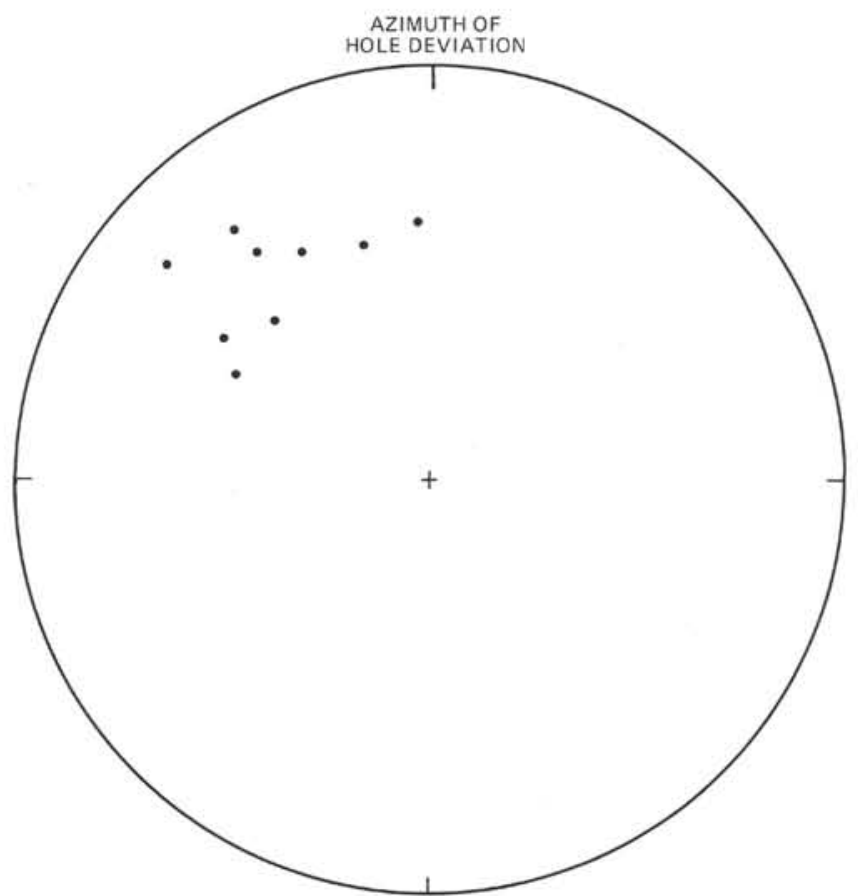

Figure 4. Stable remanence directions for nine bedded samples from lower part of hole. The primitive circle represents the plane of the bedding. The declinations are with respect to the azimuth of the hole deviation, which is assumed to be the same in each sample, and is here arbitrarily shown in the direction normally considered to be north. Equal area projection. See text for further details.

direction and a close grouping of remanence directions would also produce the above result. (The seismic profiles indicate that there might be shallow dips, less than 5 degrees, in the lowest $100 \mathrm{~m}$ of the hole.)

The inclinations of the NRM and the mean stable remanence of these nine bedded samples were determined by noting the angle between the remanence directions and the bedding; these inclinations are given in Table 1. The mean declination of the stable remanence of these nine samples ( $37.4^{\circ}$ counterclockwise, relative to the azimuth of the hole deviation) was then used to correct the stable inclination of all the remaining (i.e., unbedded) samples from depths below 1369 meters (i.e., for that part of the hole where the deviation was greater than $6^{\circ}$ ). To perform this correction, the amount of deviation from the vertical must be known for each sample. Between 1369 and about 1575 meters, the evidence of the attitude of the bedding in the cores indicates that it increases gradually from about $6^{\circ}$ to $11^{\circ}$ roughly consistent with the inclinometer measurements. For samples in this depth range, these were the deviation values used in the corrections. Between depths of 1575 and 1730 meters, however, bedding attitudes indicated a small increase from about 11 degrees to 12 degrees, whereas the only inclinometer measurement in this part of the hole (at 1696 meters), indicated a deviation of $23^{\circ}$. It was decided to ignore the inclinometer measurement and use the deviation angles indicated by the bedding for the corrections in this interval. If the inclinometer measurement was correct, then most of the 
corrections to inclinations in this interval are too small by a factor of about two. The relationship between the deviation direction and the average stable remanence direction is such that the apparent inclination of samples is increased by an amount equal to about two-thirds of the amount of deviation, so the correction reduces the inclinations by the same amount, i.e., from about $4.0^{\circ}$ at 1369 meters (deviation $6^{\circ}$ ) to about $8.5^{\circ}$ at 1730 meters (deviation $12^{\circ}$ ).

In the unbedded samples from below 1369 meters for which stable magnetizations were obtained, the NRM inclinations were corrected by assuming the standard declination between the azimuth of the hole deviation and the stable remanence direction, then noting the relative declination between the stable direction and the NRM direction. Except for those few which had good bedding and could be corrected directly, NRM inclinations were not corrected in samples for which stable magnetizations were not obtained.

\section{Stable Inclinations}

The variation of stable inclination with depth is shown in Figure 5. There are approximately equal numbers of normal and reversed magnetizations down to a depth of 889 meters, whereas all but 3 of 116 magnetizations are normal below this depth. The histogram of stable inclinations (Figure 6) illustrates the preponderance of positive inclinations resulting from this long normal interval, and also shows the clear bimodality of inclinations, thus suggesting that we are measuring stable normal and reversed magnetizations. The mean inclination of the 44 normal samples down to 889 meters is $34.0^{\circ}$, and the mean inclination of the 56 reversed samples in this interval is $-28.4^{\circ}$. This small discrepancy presumably implies that, in spite of demagnetizing each sample to an end-point, there is a small and presumably secondary normal overprint that has not been removed.

\section{Storage Magnetizations}

E. A. Hailwood and W. O. Sayre (personal communication) noted that when some Leg 48 deep-sea sediment samples, which were demagnetized and measured onboard Glomar Challenger a day or so after recovery, were demagnetized and remeasured ashore a few months later, their stable remanence directions differed considerably. To check this on Leg 47B, a number of samples which yielded stable magnetizations onboard ship was demagnetized and measured again at least 6 months later. Some samples from above the Upper Cretaceous hiatus, which had shown stable end-points at fields of 150 to 400 Oe onboard ship, became unstable at fields of around 150 to 250 Oe when demagnetized ashore and could not be used for this test. However, 34 samples ( 13 from above the hiatus and 21 from below) were stable when demagnetized again ashore. All but two of these had magnetization directions within $15^{\circ}$ of the directions measured onboard ship, and the majority had directions within $5^{\circ}$ of the onboard directions. The 34 samples yielded a mean inclination of $35.15^{\circ}$ when measured onboard ship, and $34.33^{\circ}$ when measured ashore. This indicates that the small differences of inclination values between ship and shore measurements are essentially random, and that no systematic effect is present.

As a further test for spurious stable components acquired during storage, the mean stable inclination of samples measured onboard ship was compared with the mean stable

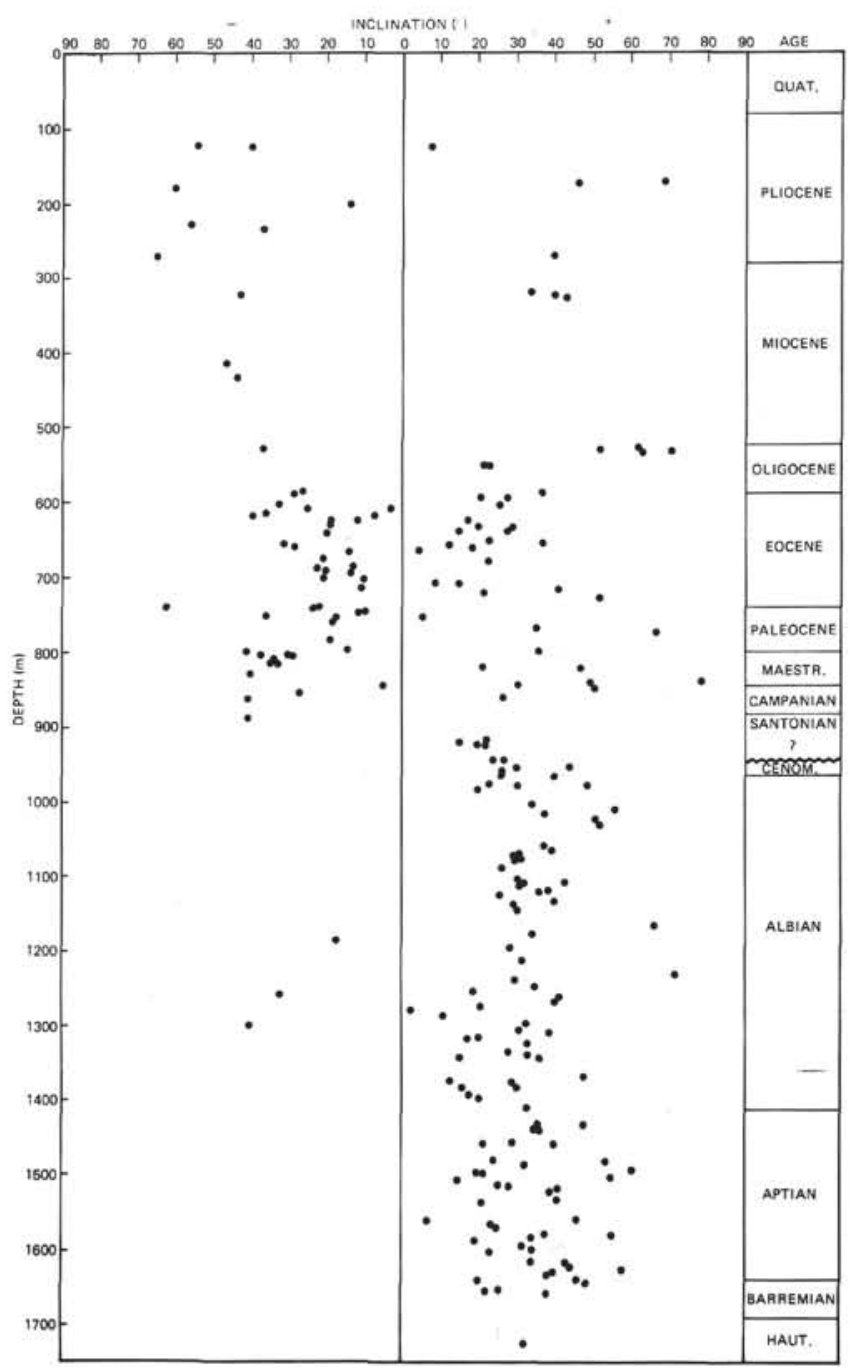

Figure 5. Variation of stable inclination with depth.

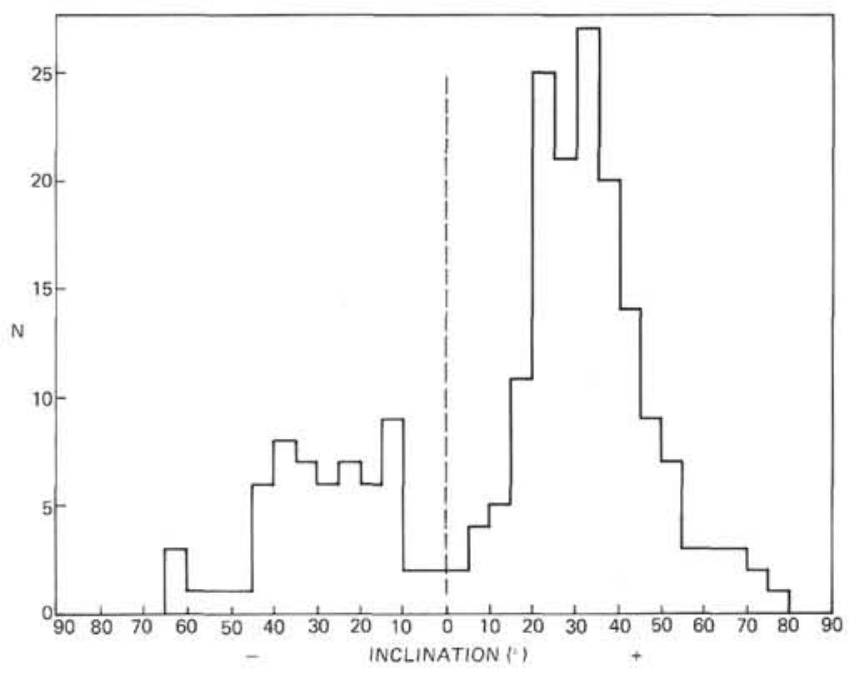

Figure 6. Histogram of stable inclinations.

inclination of samples measured ashore. The comparison included all samples from a depth of 537 meters to the bottom of the hole; samples from depths shallower than 537 
meters were excluded because they were all measured onboard ship, and their inclinations were generally steeper than deeper samples so that their inclusion would have unfairly biased the result. The mean inclination of 46 samples measured onboard ship was $31.43^{\circ}$, and the mean inclination of 156 samples measured ashore was $31.36^{\circ}$. This indicates that, in general, no systematic change in inclination occurred between the time cores arrived on the deck of Glomar Challenger and when they were measured ashore 6 to 9 months later. A detailed comparison of the results shows that the almost exact correspondence of inclinations occurs partly because the ship and shore measurements tend to be concentrated in different depth intervals. The samples from the 537-to 955-meter interval tended to have inclinations $4^{\circ}$ to $6^{\circ}$ shallower when measured ashore than samples measured aboard ship. For the depth range 955 to 1730 meters, shore inclinations tended to be slightly (less than $1^{\circ}$ ) steeper than ship inclinations.

\section{DISCUSSION}

\section{Magnetic Stratigraphy}

Discontinuous coring at depths to about 500 meters clearly does not allow recognition of a complete sequence of magnetic reversals. Coring between 500 and 900 meters was generally continuous and recovery good, but the 83 stable magnetizations obtained over this interval represent an average of only a single observation every 5 meters. With sedimentation rates of 5 to $10 \mathrm{~m} / \mathrm{m}$.y. over much of this interval, this represents less than two observations per m.y.; combined with the rather irregular spacing of the observations, this paucity of data precludes definition of a complete reversal sequence. It is thus apparent that this study cannot contribute to the detailed magnetostratigraphy of the Upper Cretaceous and Tertiary. It can, however, furnish some information about the duration of the long Cretaceous normal interval.

Apart from the three isolated reversed samples within the normal interval, the oldest reversed sample (398D-51-1, 45 $\mathrm{cm}$ ) occurs in the uppermost Santonian. This is reasonably consistent with the results of Alvarez et al. (1977), who place the end of the long normal interval at the Santonian/ Campanian boundary. The Mesozoic magnetic polarity time scale of Larson and Pitman (1972), based on marine magnetic anomalies, shows the normal interval beginning close to the Barremian/Aptian boundary. The time scale of Larson and Hilde (1975) is generally similar, but shows a reversed interval within the Aptian as a result of the newly discovered $M-O$ anomaly. Both time scales show reversals throughout the Barremian (corresponding to anomalies $M 1$ to $M 4$ ), and including one long reversed interval of about 3 m.y. duration. The Cretaceous time scale of van Hinte (1976) shows a short zone of mixed polarity in the upper Albian, and also an interval of reversed polarity (the Gatan zone of Pechersky and Khramov, 1973) in the uppermost Aptian, which possibly correlates with marine anomaly MO. Van Hinte shows the rest of the Aptian and most of the Barremian as normal, and places the beginning of the long normal interval in the lowermost Barremian.

At Site 398, apart from the three reversed samples in the middle Albian, there are consistently normal stable magnetizations down to a depth of 1659 meters (probably up- permost lower Barremian). Between 1659 and 1740 meters (upper Hauterivian), the NRM intensities are so low that demagnetization was attempted on only one sample (398D-137-1, $26 \mathrm{~cm}$ ) which also yielded a normal stable magnetization. These results thus suggest that the long Cretaceous normal interval extends back at least as far as approximately middle Barremian, and are thus more consistent with the time-scale of van Hinte (1976) than with the other versions. There is, however, no evidence at Site 398 of a reversed interval within the Aptian corresponding to the Gatan Zone of van Hinte or the $M O$ anomaly of Larson and Hilde (1975). The 38 stable magnetizations within the Aptian represent an average of about five observations per m.y., and the largest observation gap represent about 0.6 m.y., so it would appear unlikely that a reversed interval of the duration suggested ( 1 to $2 \mathrm{~m}$.y.) has been missed. It is noted, however, that there is some indication (see Sigal, this volume) that there might be a minor hiatus in the region of the Aptian/Albian boundary. Samples from the lower part of the normal interval were particularly carefully demagnetized to check that they did not contain a reversed component masked by a normal overprint. Thus, of the 61 samples giving stable normal magnetizations below 1303 meters, 29 were demagnetized to fields of at least $400 \mathrm{Oe}$, and 7 to fields of at least $1000 \mathrm{Oe}$, without showing any indications of a reversed component. The three reversely magnetized samples from the middle Albian may represent very brief reversed events such as have been reported from Cretaceous sediments by Keating et al. (1975).

\section{Inclinations}

Figure 7 shows both positive and negative stable inclinations on the same axis, plotted against depth. Although there is appreciable scatter in inclination values, a fairly consistent pattern emerges when inclinations are averaged over a dozen or so samples. Variation of the average inclination with depth is shown in Figure 7 by means of a 13-point running mean. This diagram also shows the anticipated variation of inclination with depth at Site 398 using the present-day inclination for a centered axial dipole, and the Cenozoic and Cretaceous paleocontinental maps of Smith and Briden (1977) and Van der Voo and French (1974). Smith and Briden used sea-floor spreading data to establish the relative positions of the continents, then reliable paleomagnetic data to determine their absolute latitudinal and relative longitudinal positions. Van der Voo and French used a similar technique but confined themselves to the Atlantic-bordering continents. The variation of inclination with depth expected at Site 398 according to these two reconstructions is generally similar, except that the middle and Upper Cretaceous and lowermost Cenozoic reconstructions of Smith and Briden give inclinations about $5^{\circ}$ steeper than the single Upper Cretaceous reconstruction of Van der Voo and French (1974).

Average inclinations are consistently shallower throughout the hole than would be expected from the continental reconstructions. Because there were only 22 observations between 125 and 550 meters, the variation of average inclination with depth is imprecisely defined. Were it not for the two anomalously low inclinations at 126 and 202 meters, the average inclination between 120 and 330 meters would be about $50^{\circ}$ rather than $45^{\circ}$ shown, that is, only about $5^{\circ}$ 


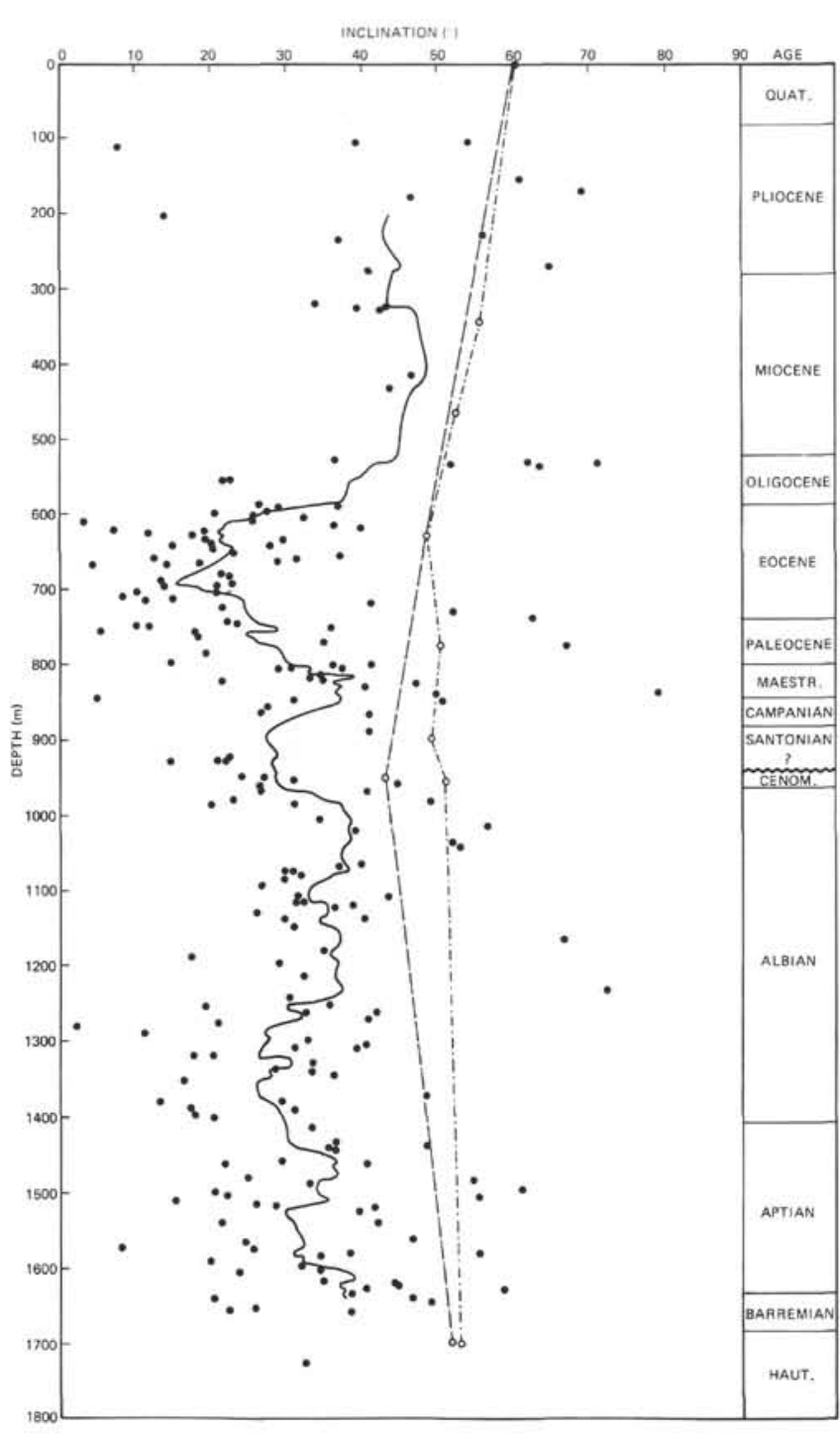

Figure 7. Positive and negative stable inclinations on the same axis, plotted against depth. The solid line is a 13point running mean. The dot-dash line and the dashed line show the expected variation of inclination with depth at Site 398, using the reconstructions of Smith and Briden (1977) and Van der Voo and French (1974), respectively.

shallower than expected. Between 580 and 750 meters, average inclinations are typically between $20^{\circ}$ and $25^{\circ}$, about $25^{\circ}$ shallower than the expected inclination. Because of the small number of observations in the 330 to 580 meter inter$\mathrm{val}$, it is difficult to decide whether there is a sharp or gradual change from the high inclinations above 330 meters to the low inclinations below 580 meters. Between 750 meters and the bottom of the hole, average inclinations are mainly within the range $28^{\circ}$ to $37^{\circ}$, about $15^{\circ}$ shallower than expected.

As noted above, in samples from 125 to 889 meters, there is probably a small secondary normal overprint that has not been removed by demagnetization. When average inclinations are calculated, however, this effect is largely removed because there are approximately equal numbers of normal and reversed samples. If the same effect is present in the samples from below 889 meters, which are virtually all normal, it will not be removed by averaging, and the average inclinations shown in Figure 7 will be about $2^{\circ}$ to $3^{\circ}$ too high.

Early laboratory experiments on detrital remanent magnetization (DRM) indicated that remanence inclinations were always shallower than the field inclination at the time of deposition (e.g., King, 1955). More recent experiments on synthetic sediments (Irving and Major, 1964) and on deep-sea sediments (Kent, 1973) have shown that a stable detrital remanence can be produced by post-depositional alignment of the magnetic grains, and that this postdepositional DRM has no inclination error. Løvlie (1974, 1976) redeposited deep-sea sediments and found that the magnetization did not become fixed until 5 to 10 days after deposition; this clearly implies post-depositional alignment of the magnetic grains. Opdyke and Henry (1969) found that the average inclinations in 52 deep-sea cores agreed with that expected from an axial dipole field; this suggests that in nature these sediments have a post-depositional DRM that accurately records the inclination of the ambient field. It therefore appears unlikely that the low inclinations reported here result from a depositional inclination error of the type reported by King, and it is possible that compaction of the sediments, i.e., thickness reduction caused by the weight of overlying material, may be responsible. The cores studied by Opdyke and Henry were restricted to the uppermost 5 to 15 meters of sediment, where compaction effects are unlikely to be important; the present study pertains to depths of 125 to 1740 meters.

Keen (1963) reported a shallowing of inclination with depth in the uppermost few meters of some deep-sea cores from the northeast Atlantic, and also an inverse correlation between inclination and water content, which he attributed to a compaction effect. In view of the results of Opdyke and Henry on a large number of cores, this shallowing of inclination resulting from compaction at shallow depth does not appear to be a general phenomenon in deep-sea sediments. Results from more deeply buried sediments on previous DSDP legs appear to be conflicting in inclination errors. Sclater and Cox (1970) noted that the average inclination of Campanian sediments from a depth of 400 meters at Site 10 agreed closely with the predicted inclination. Green and Brecher (1974) found that 41 samples from a depth of 480 to 600 meters at Site 263 yielded an average inclination only about $3^{\circ}$ shallower than predicted. Blow and Hamilton (1975) found that the internal agreement of paleolatitude data from DSDP cores in the Indian Ocean is markedly improved if an inclination error of $15^{\circ}$ to $20^{\circ}$ is assumed for rapidly deposited clastic sediments, but no such error is assumed for slowly deposited pelagic and hemipelagic sediments. Cockerham and Jarrard (1976) found that at a depth of about 600 meters at Site 317, inclinations in sediments were consistently about $20^{\circ}$ shallower than the inclinations in underlying basalts. They suggest that the sediment inclinations may have been shallowed by compaction, but note that if the basalt results did not average out the effects of secular variation, then that would explain the discrepancy. Lowrie and Alvarez (1975) found that there was no significant change in inclination through the 400 -meter section of the Scaglia Rossa pelagic limestone at Gubbio, Italy, and 
that the mean inclination agreed closely with the inclination predicted for the site by the reconstruction of Van der Voo and French. This section is considered to have been buried to a depth of at least $1 \mathrm{~km}$ (Arthur and Fischer, 1977); these results therefore suggest either that inclinations have not been affected by compaction or that fairly early cementation of these limestones prevented the later stages of compaction, which are perhaps mainly responsible for any shallowing effect.

An indication of the amount by which the thickness of argillaceous sediments is reduced during compaction can be seen from the study of Baldwin (1971), who used a large amount of published data to construct an average porositydepth curve for depths down to about 3000 meters. Porosity values at various points on this curve have been converted to relative thickness (see Table 2 ) in the manner described by Baldwin, assuming simple compaction without any addition or loss of solid material. The thicknesses are given relative to the thickness at a depth of 0.3 meters, because it seems likely that post-depositional DRM does not become fixed until approximately this depth.

Although there appears to be considerable uncertainty about the details of the actual compaction process, and in particular about the extent to which mineral grains become reoriented (Rieke and Chilingarian, 1974), it would seem physically reasonable that the considerable reduction in thickness indicated in Table 2 should in some circumstances have a shallowing effect on remanence inclinations. The shape of the grains carrying the remanence is likely to be an important factor controlling this shallowing effect. Grains which are markedly non-equidimensional, such as elongate needles, will presumably experience the largest rotations toward the horizontal during compaction. The remanence in these grains probably will be aligned along the long axis of the needle, such that the shallowing of inclination will be approximately equal to the average amount of rotation. There is some evidence (Løvlie et al., 1972) that the remanence carriers in deep-sea sediments have only slight shape anisotropies, with length/width ratios of around 1.5 or less. Grains of this shape should experience smaller rotations than more elongate grains, although it should be noted that they could experience large rotations if they were attached to larger non-equidimensional grains which were rotating. In grains with only slight shape anisotropy, there is probably no relationship between the long axis of the grain and the remanence direction. Before compaction, the sediment probably contains an assemblage of magnetic grains with their remanence directions aligned by some post-depositional process, but whose long axes are arranged ran-

TABLE 2

Thickness Reduction of Argillaceous Sediments With Depth (based on Baldwin, 1971)

\begin{tabular}{cc}
\hline Depth $(\mathrm{m})$ & Relative Thickness \\
\hline 0.3 & 100 \\
5 & 74 \\
10 & 66 \\
100 & 45 \\
500 & 33 \\
1000 & 29 \\
2000 & 27 \\
\hline
\end{tabular}

domly. When compaction rotates these grains, it will be equivalent to rotation about a random set of horizontal axes and, by analogy with the rolling sphere model of depositional inclination error (Griffiths et al., 1960), the effects on inclination will not average out but will produce an overall shallowing which will be somewhat less than the average amount of grain rotation. This would also apply to equidimensional grains being rotated about random horizontal axes, owing to physical attachment to other rotating grains.

Table 2 indicates that an appreciable reduction of thickness occurs in the upper 5 to 10 meters of sediment. The results of Opdyke and Henry (1969), that no shallowing of inclination occurs over this interval in deep-sea sediments, might be taken to indicate that compaction does not modify remanence inclinations. There is considerable evidence (Richards and Hamilton, 1967), however, that deep-sea sediments experience much less compaction than other finegrained sediments, at least in the superficial layers. This is thought to be related to their slow rate of accumulation, and the development of chemical intergrain bonding, which greatly increases the strength of the sediment. Silva et al. (1976) have also suggested that in deep-sea sediment there is an upper layer where compaction is inhibited by particle bonding, but more normal consolidation may be occurring at deeper levels. If true, this would explain the lack of inclination errors in the 52 deep-sea cores studied by Opdyke and Henry. It is also possible that the early stages of compaction have little effect on remanence inclinations, but that the shallowing occurs mainly after early compaction has brought the mineral grains into more intimate contact.

The variation of porosity with depth at Site 398 is illustrated in Williams and Mountain (this volume). Two determinations at around 35 meters indicate porosities of about 58 per cent, and porosities between this depth and about 375 meters show some scatter but average around 55 per cent. Between about 375 and 450 meters, porosities fall to about 40 per cent, and from 450 to 1400 meters, they consistently average around 40 per cent, although there is some scatter of individual values in the upper part of this interval. Near 1400 meters, porosities decrease rather abruptly to about 30 per cent, and between 1400 meters and the bottom of the hole, they decrease irregularly to around 20 per cent.

There are no porosity determinations for the upper few meters of sediment at Site 398, but we may estimate the original porosities of the sediments present from published values of porosities in the uppermost few meters of deep-sea sediments. Thus, Hamilton (1974) published average porosities for abyssal plain and hill sediments from the 0 to $30-\mathrm{cm}$ depth interval; calcareous oozes of clayey-silt and silty-clay grade have an average porosity of 70 per cent, and the average porosity for terrigenous sediments of clayey-silt grade and finer is 80 per cent. Gealy (1971) found that at DSDP Sites 62 and 64, the nannofossil oozes in the uppermost few meters had porosities of about 70 per cent, and the calcareous pelagic clays at Site 63 had porosities of about 80 per cent. It would therefore seem reasonable to assume that the oozes and chalks at Site 398 originally had porosites of about 70 per cent, and the mudstones, claystones, and shales originally had porosities of about 80 per cent. Apart from the nannofossil limestones in the lowermost 60 meters, cementation is not significant at this site, so these porosity 
values can be used to determine the thickness reductions that have occurred.

If the simplifying assumption is made that the sediments shallower than 700 meters are entirely calcareous and had original porosities of 70 per cent, then the porosities of around 55 per cent in the 30 -to 375 -meters interval indicate a reduction to about 60 per cent of the original thickness, and the porosities of around 40 per cent in the 450 -to 700 meter interval indicate a reduction to about 45 per cent. If it is assumed that the sediments deeper than 700 meters are entirely terrigenous and had original porosities of 80 per cent, then the porosities of around 40 per cent in the 700-to 1400 -meter interval indicate a reduction to about 33 per cent of the original thickness, and the porosities of around 30 per cent below 1400 meters indicate a reduction to about 29 per cent. The porosities of around 20 per cent and less in the lowermost part of the hole are probably produced both by compaction and cementation, and cannot be used for thickness calculations. It is apparent that there have been appreciable reductions in sediment thickness at this site.

The significance of the unusually low average inclinations, $20^{\circ}$ to $25^{\circ}$ in the 580 -to 750 -meter interval, is uncertain. The porosity data do not indicate any abnormal compaction over this interval, and there is no obvious evidence that the magnetic mineralogy is different. The low inclinations could, of course, be explained by postulating a temporary excursion of the Iberian plate to latitudes about $5^{\circ}$ to $7^{\circ}$ farther south. The appreciable scatter of inclination values also requires some explanation. Failure to average out secular variation may be partly responsible, particularly for samples from intervals with high sediment accumulation rates. It is also possible that variable removal of secondary normal overprints could be responsible; over the 500-to 900-meter interval, only one reversed sample has an inclination of greater than $45^{\circ}$, whereas ten normal samples have inclinations greater than this value. If the shallowing of inclination reported here is real and caused by compaction, then it is possible that some of the scatter results from variation in the amount of compaction, or perhaps in the shapes of the remanence carriers, so that the same amount of compaction produces a variable shallowing effect.

To obtain an estimate of the average shallowing of inclination at Site 398, the mean of all 194 stable inclinations from between 550 meters and the bottom of the hole was computed and compared with the average inclination over this interval to be expected from the continental reconstructions. An upper limit of 550 meters was chosen because the most marked shallowing of inclination at Site 398 occurs between 330 and 550 meters, and because it is assumed that any compaction effect on inclination will be largely complete at about this depth. Briden and Ward (1966) noted that the average inclination from borehole data will always be shallower than the inclination of the average direction of magnetization (i.e., the true inclination), and they provided a method by which the inclination of the average direction can be estimated even when declination data are lacking. The average inclination for the 194 stable magnetizations deeper than 550 meters is $30.16^{\circ}$, and the inclination of the average direction calculated by the method of Briden and Ward is $32.4^{\circ}$. The predicted average inclination for this interval is about $49^{\circ}$ and, if the reconstructions are correct, the Site 398 inclinations deeper than 550 meters are typically about $17^{\circ}$ too shallow. It is unfortunate that, because of the few observations down to 550 meters, it is not possible to construct a reliable curve showing the variation of average inclination over this interval, since it is over this depth range that the major shallowing of inclination caused by compaction is likely to occur. If the inclinations at Site 398 have not been modified by compaction and accurately record the ambient field just after deposition, then this part of the Iberian plate must have been approximately $10^{\circ}$ to $15^{\circ}$ farther south than previously supposed during the Cretaceous and Paleocene, and possibly about $20^{\circ}$ farther south during the Eocene and early Oligocene.

\section{ACKNOWLEDGMENTS}

I thank Dr. E. A. Hailwood and Professor J. C. Briden for critically reading the manuscript, and my fellow scientists on Leg 47B for many useful discussions.

\section{REFERENCES}

Alvarez, W., Arthur, M. A., Fischer, A. G., Lowrie, W., Napoleone, G., Premoli Silva, I., and Roggenthen, W. M., 1977. Upper Cretaceous-Paleocene magnetic stratigraphy at Gubbio, Italy, (V) Type Section for the Late CretaceousPalaeocene geomagnetic reversal time scale, Geol. Soc. Am. Bull., v. 88, p. 383-389.

Arthur, M. A. and Fischer, A. G., 1977. Upper CretaceousPaleocene magnetic stratigraphy at Gubbio, Italy, (I) Lithostratigraphy and sedimentology, Geol. Soc. Am. Bull., v. 88, p. 367-371.

Baldwin, B., 1971. Ways of deciphering compacted sediments, $J$. Sediment. Petrol., v. 41 , p. 293-301.

Blow, R. A. and Hamilton, N., 1975. Paleomagnetic evidence from DSDP cores of northward drift of India, Nature, v. 257, p. $570-572$.

Briden, J. C. and Ward, M. A., 1966. Analysis of magnetic inclination in bore cores, Pure Appl. Geophys., v. 63, p. 133-152.

Cockerham, R. S. and Jarrard, R. D., 1976. Paleomagnetism of some Leg 33 sediments and basalts. In Schlanger, S. O., Jackson, E. D., et al. Initial Reports of the Deep Sea Drilling Project, v. 33: Washington (U.S. Government Printing Office), p. 631-647.

Gealy, E. L., 1971. Saturated bulk density, grain density and porosity of sediment cores from the western equatorial Pacific. In Winterer, E. L., et al., Initial Reports of the Deep Sea Drilling Project, v. 7, Part 2: Washington (U.S. Government Printing Office), p. 1081-1104.

Green, K. E. and Brecher, A., 1974. Preliminary paleomagnetic results for sediments from Site 263, Leg 27. In Veevers, J. J., Heirtzler, J. R., et al., Initial Reports of the Deep Sea Drilling Project, v. 27: Washington (U.S. Government Printing Office), p. 405-413.

Griffiths, D. H., King, R. F., Rees, A. I., and Wright, A. E., 1960. The remanent magnetism of some recent varved sediments. Roy. Soc. London Proc., v. A256, p. 359-383.

Hamilton, E. L., 1974. Prediction of deep sea sediment properties:-State-of-the-Art. In Inderbitzen, A. L. (Ed.), Deep-sea sediments, physical and mechanical properties: New York (Plenum Press), p. 1-44.

Irving, E. and Major, A., 1964. Post-depositional detrital remanent magnetization in a synthetic sediment, Sedimentology, v. 3 , p. 135-143.

Keating, B., Helsely, C. E., and Pessagno, E. A., 1975. Reversed events within the Late Cretaceous normal polarity inter- 
val (abstract), EOS Trans. Am. Geophys. Union, v. 56, p. 354.

Keen, M. J., 1963. Magnetization of sediment cores from the eastern basin of the North Atlantic Ocean, Deep-Sea Res., v. 10 , p. $607-622$.

Kent, D. V., 1973. Post-depositional remanent magnetization in deep-sea sediment, Nature, v. 246, p. 32-34.

King, R. F., 1955. The remanent magnetism of artificially deposited sediments, Monthly Notices Roy. Astron. Soc., Geophys. Suppl., v. 7, p. 115-134.

Larson, R. L. and Hilde, T. W. C., 1975. A revised time scale of magnetic reversals for the Early Cretaceous and Late Jurassic, J. Geophys. Res., v. 80, p. 2586-2594.

Larson, R. L. and Pitman, W. C., III., 1972. World-wide correlation of Mesozoic magnetic anomalies, and its implications, Geol. Soc. Am. Bull., v. 83, p. 3645-3662.

Løvlie, R., 1974. Post-depositional remanent magnetization in a re-deposited deep-sea sediment, Earth Planet. Sci. Lett., v. 21 , p. $315-320$.

, 1976. The intensity patterns of post-depositional remanence acquired in some marine sediments deposited during a reversal of the external magnetic field, Earth Planet. Sci. Lett., v. 30 , p. $209-214$.

Løvlie, R., Lowrie, W., and Jacobs, M., 1971. Magnetic properties and mineralogy of four deep-sea cores, Earth Planet. Sci. Lett., v. 15, p. 157-168.

Lowrie, W. and Alvarez, W., 1975. Paleomagnetic evidence for rotation of the Italian Peninsula, J. Geophys. Res., v. 80, p. $1579-1592$.
Molyneux, L., 1971. A complete results magnetometer for measuring the remanent magnetization of rocks, Geophys. J. Roy. Astron. Soc., v. 24, p. 429-435.

Opdyke, N. D. and Henry, K. W., 1969. A test of the dipole hypothesis, Earth Planet. Sci. Lett., v. 6, p. 139-151.

Pechersky, D. M. and Khramov, A. N., 1973. Mesozoic paleomagnetic scale of the U.S.S.R., Nature, v. 244 , p. 499 501 .

Rieke, H. H., III, and Chilingarian, G. V., 1974. Compaction of argillaceous sediments: Amsterdam (Elsevier Scientific Publishing Company).

Richards, A. F. and Hamilton, E. L., 1967. Investigations of deep-sea sediment cores, III Consolidation. In Richards, A. F. (Ed.), Marine geotechnique: Urbana (University of Illinois Press), p. 93-117.

Sclater, J. G. and Cox, A., 1970. Paleolatitudes from JOIDES deep sea sediment cores, Nature, v. 226, p. 934-935.

Silva, A. J., Hollister, C. D., Laine, E. P., and Beverly, B. E., 1976. Geotechnical properties of deep sea sediments: Bermuda Rise, Marine Geotechnol., v. 1, 195-232.

Smith, A. G. and Briden, J. C., 1977. Mesozoic and Cenozoic paleocontinental maps: Cambridge (Cambridge University Press).

Van der Voo, R. and French, R. B., 1974. Apparent polar wandering for the Atlantic-bordering continents: Late Carboniferous to Eocene, Earth-Sci. Rev., v. 10, p. 99-119.

van Hinte, J. E., 1976. A Cretaceous time scale, Am. Assoc. Petrol. Geol. Bull., v. 60, p. 498-516. 